\title{
Use of protective equipment by in-line skaters: an observational study
}

\author{
D J Beirness, R D Foss, K J Desmond
}

\begin{abstract}
Objective-To determine the extent of protective equipment use (that is, helmets, wrist guards, elbow pads, knee pads) in a representative sample of in-line skaters.

Setting-Fifteen municipalities throughout the province of British Columbia.

Method-A province-wide observational survey was conducted in the summer of 1999. Skaters were observed at four types of sites (commuter, recreational, neighbourhood, general community) in $15 \mathrm{mu}-$ nicipalities to provide a representative sample of in-line skaters.

Results-The observed use of protective equipment by the 877 in-line skaters was relatively low: wrist guards $25 \%$, helmets $13 \%$, elbow pads $14 \%$, and knee pads $10 \%$. Conclusion-Despite the availability of relatively inexpensive protective equipment, few in-line skaters take advantage of the opportunity to protect themselves from injury. Policies and programs that serve to increase the use of protective equipment by in-line skaters are needed to help reduce the frequency of skating related injuries.

(Injury Prevention 2001;7:51-55)
\end{abstract}

Keywords: in-line skating; helmet use; protective equipment

The popularity of in-line skating has increased tremendously over the last decade in both Canada and the United States. The International In-Line Skating Association (IISA) reports that in a 1997 survey of Americans over the age of 7, the National Sporting Goods Association found that 26.6 million Americans participated in in-line skating. ${ }^{1}$ This is an increase of $4.1 \%$ from the previous year and a $639 \%$ increase from 1990

As the popularity of the sport has increased, so too have the injuries associated with it. Quoting data from the National Electronic Injury Surveillance System (NEISS) in the United States, the IISA notes that in-line skating injuries have escalated from 29000 in 1992 to 102911 in 1996 , an increase of $255 \%$. Over the same period of time, the number of skaters is estimated to have increased from 9.7 million to 28.9 million, a change of $198 \%$. The injury rate per 1000 skaters increased from 2.99 in 1992 to 3.56 in 1996 .

Numerous studies have documented the nature and severity of injuries associated with in-line skating over the years using either information from NEISS, hospital based data, or both..$^{2-18}$ Invariably, the wrist and forearm are the most frequently reported sites of injury. ${ }^{8-18}$ For example, injury statistics from NEISS for 1996 reveal that the wrist was the most frequent site of injury, accounting for $24.2 \%$ of all in-line skating injuries. The forearm accounted for $13.5 \%$ of injuries, followed by the elbow (7.6\%), knee $(6.8 \%)$, and head $(4.1 \%)$. Together, injuries to these areas accounted for over half of all in-line skating related injuries.

In Canada, data from the Canadian Hospitals Injury Reporting and Prevention Program (CHIRPP) indicate that in 1998, 962 in-line skaters were seen at emergency departments at the 15 reporting hospitals. ${ }^{18}$ Because the majority of CHIRPP data come from pediatric hospitals, $93 \%$ injuries to in-line skaters in this database involved patients under 20 years of age. The most frequent sites of injury were the forearm $(24 \%)$ and wrist $(20 \%)$. The elbow was the site of $9.5 \%$ of injuries and the knee $3.5 \%$. Head injuries accounted for $5.6 \%$ of the total.

Relatively inexpensive protective equipment for these vulnerable areas is available and its use has been shown to be effective in reducing the risk of injury. Using a case-control study design of patients reporting to an emergency department for skating related injuries, Schieber et al found that after controlling for age and sex the odds of a wrist injury were 10.4 times greater for those not wearing wrist guards as compared with those who did. ${ }^{19}$ The risk of elbow injury was 9.5 times greater for those who did not wear elbow pads compared with those who did. The odds for knee injury were somewhat raised for those not wearing knee pads (2.2) but not significantly so. Unfortunately, given the relatively small number of head injuries, it was not possible to evaluate the effectiveness of helmets in reducing head injuries. However, helmets are known to be highly protective against serious head injury. $^{20}$

Much of the information available about the use of protective gear has come from data obtained from injured patients seen in an emergency department or a trauma facility. ${ }^{13171921}$ Few observational studies have been conducted to determine the extent to which protective gear is worn by in-line skaters while they are skating. Of those that have been done, ${ }^{42-25}$ most are limited to particular areas or age groups and report highly variable findings. For example, in an observational study of 123 skaters in various locations throughout Winnipeg, Manitoba, Warda et al found very low rates of protective equipment use (wrist guards $16 \%$, knee pads $10 \%$, elbow 
pads $7 \%$, helmets $12 \%$ ). Jacques and Grzesiak observed primarily adult skaters at parks and recreational pathways in Oakland County, Michigan, and found wrist guard use rates as high as $65 \% .^{24}$

Large scale observational studies of all skaters conducted in a variety of locations are needed to provide a more general picture of who is wearing which types of protective equipment and where they are skating. This information could then be used to help develop programs to target specific groups of skaters in an attempt to increase their use of protective gear while in-line skating. Such was the purpose of this study.

\section{Methods}

Observations of in-line skaters were made as part of a province-wide survey of bicycle helmet use in British Columbia. In this context, the bicycling population was not viewed as a homogenous group, but rather as being comprised of several subpopulations. For example, persons who ride bicycles primarily as a means of transportation might be thought of as commuters, whereas those who ride primarily for pleasure might be identified as recreational cyclists. In an effort to observe the various types of cyclists, observation sites were defined as commuter, recreational, neighborhood, and "general community". Although the sampling of observation sites was done with bicyclists in mind, skaters, too, can be separated into the same general subpopulations. Hence, the same sites were ideal for observing in-line skaters as well.

Four types of observation sites were defined as follows. (Greater detail concerning definition and sampling of observation site locations is provided in Foss et al. ${ }^{26}$ )

Commuter sites were located along major roadways likely to be used by cyclists and skaters going to or from work. Observation times were chosen to coincide with commuting hours - that is, early morning and late afternoon/early evening.

Recreational sites were defined as bicycle paths, recreational pathways, or roads within recreational areas (for example, parks).

Neighborhood sites were defined as the attendance catchment areas of elementary schools. Rather than observing at a fixed location, observers canvassed the area for cyclists and skaters by systematically driving every street in the area.

General community observations were collected by driving systematically through each of the selected communities. The primary purpose of these observations was to obtain information on casual cyclists and skaters who might not have been captured at the other types of sites.

Communities with a population of 10000 or greater were eligible for selection. Individual communities were sampled with a probability proportional to their populations. This resulted in 15 distinct communities being selected with two being selected more than once. Several observation sites of each type were randomly selected within each sampled community. Observations were conducted at each of 222 sites for approximately 30 minutes on each of two separate occasions.

An attempt was made to observe and record estimated age, sex, protective equipment use (helmet, elbow pads, wrist guards, knee pads), and skater location (sidewalk, road, pathway, off-road area such as a parking lot or driveway) for every skater that passed the observer's location. Five categories were used to estimate age: $<6,6-15,16-30,31-50,>50$. The small number of very young $(n=12)$ and older $(n=$ 8) skaters resulted in these groups being collapsed into the adjacent categories for analysis.

A day long observer training session was held immediately before data collection. Interobserver agreement on all items was very high, exceeding $95 \%$. Agreement on age was lowest, but still in excess of $95 \%$.

Analyses were conducted using weighted data, to reflect the varying likelihood of selection depending on size of community, type of site, and amount of time spent collecting data at various types of sites. In addition, adjustments to variance estimates for the odds ratios were incorporated to reflect increased variation due to the multistage sampling design.

\section{Results}

SAMPLE CHARACTERISTICS

A total of 877 in-line skaters were observed in 15 municipalities between 1 July and 7 September 1999. The greatest proportion of skaters was observed on recreational pathways (45\%); $32 \%$ were observed while driving through communities; $14 \%$ were observed in neighborhoods; and $10 \%$ were observed at commuter sites.

Of the 877 observed skaters, $59.1 \%$ were males; $40.9 \%$ were females. Skaters between 16 and 30 years of age comprised the largest age group of skaters $(48.8 \%)$ followed by those under $16(36.4 \%)$. Only $14.8 \%$ of skaters were estimated to be over 30 years of age.

\section{PROTECTIVE EQUIPMENT USE}

The overall observed incidence of protective equipment use by skaters was relatively low. Wrist guards were the most commonly used piece of protective equipment (25\%), followed by elbow pads (14\%), helmets (13\%), and knee pads $(10 \%)$. Overall, $36 \%$ of skaters were observed wearing at least one piece of protective equipment; less than $3 \%$ wore all four types of equipment.

Table 1 displays the observed incidence of protective equipment use and the odds ratio of equipment use according to skater gender, age, type of site, and size of community. Adjusted odds ratios were estimated by fitting logistic regression models to the data, regressing each type of protective equipment on the four predictors (gender, age, site type and community location, that is, metropolitan or less urban). 


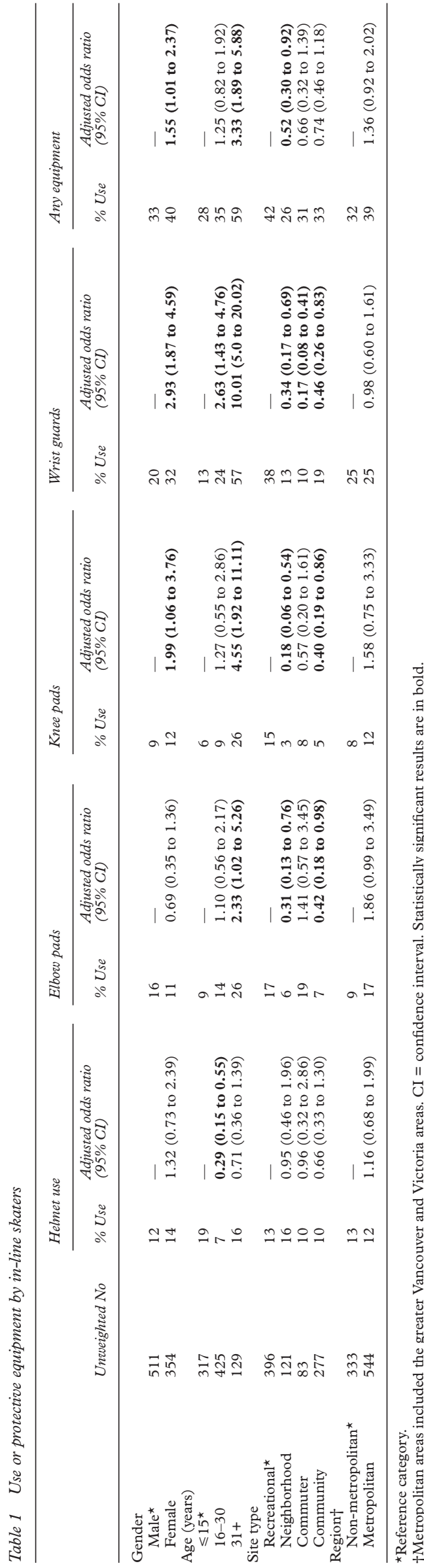

\begin{abstract}
Key points
- Relatively few in-line skaters take advantage of protective equipment.

- Wrist guards are the most commonly used piece of protective equipment $(25 \%)$ followed by elbow pads (14\%), helmets $(13 \%)$, and knee pads (10\%).

- Greater use of protective equipment has the potential to reduce the number and severity of injuries from in-line skating mishaps.
\end{abstract}

Controlling for other measured factors, female skaters were significantly more likely than males to use knee pads and wrist guards. Although equipment use was somewhat greater in metropolitan locations, when other factors are adjusted for, these differences were not statistically significant.

The use of protective equipment differed markedly by estimated skater age. The highest rates of equipment use (other than helmets) were among skaters over 30 years of age. In fact, over half $(59 \%)$ of skaters in this older age group were observed wearing at least one piece of protective equipment compared with about one quarter $(28 \%)$ of skaters under 16 years of age. Skaters age 16 to 30 were less likely than younger skaters to wear a helmet but were more likely to wear wrist guards.

The use of protective equipment also varied according to skater location (that is, type of site). Protective equipment was most frequently used by skaters on recreational pathways $(42 \%$ wore at least one piece of equipment). Skaters observed in neighborhoods and at the general community locations were significantly less likely to be wearing protective equipment. Skaters observed along commuter routes - the busiest roadways-did not generally differ in their use of equipment from those at recreational locations. This is interesting in view of the substantial age difference between skaters at these two locations. Seventy three per cent of those observed on commuter routes were 16-30, whereas only $46 \%$ of skaters at recreation sites were that age.

\section{Discussion}

The present study provides one of the most comprehensive observational surveys of protective equipment use by in-line skaters conducted to date. The sampling of communities and sites within communities provided a representative sample of in-line skaters in the province of British Columbia.

Despite the availability of relatively inexpensive protective equipment, few in-line skaters take advantage of the opportunity to protect themselves from injury. Only about one third of skaters were observed using any type of protective equipment.

The most commonly used piece of protective equipment was wrist guards. The incidence of wrist guard use was twice as high as any other single piece of equipment. Given that injuries to the wrist and forearm are the most 
frequently reported by in-line skaters, the relatively high incidence of wrist guard use would appear to suggest that skaters acknowledge the increased risk of injury to these areas and take action to protect themselves.

Although injuries to the wrist and arm are the most commonly reported, the most severe injuries occur to the head. Only 13\% of all skaters were observed wearing a helmet. If indeed skaters have some knowledge of skating related injuries, their use of wrist guards more often than helmets would suggest that they are more concerned about the frequency of injury than the severity of injury.

With the exception of helmets, older skaters were more likely than younger skaters to wear protective equipment. Older skaters may be more aware of the risks of injury or perceive greater vulnerability to injury and, hence, are more likely to protect themselves. The higher use of helmets by skaters under 16 years of age may reflect parental influence on the youngest of skaters.

The lower likelihood of protective equipment use observed in neighborhood and general community locations relative to that observed on recreational pathways or on commuter routes suggests that casual skaters (that is, those skating around communities) are less concerned about, or less aware of, the risk of injury than are more serious skaters (that is, those skating for exercise/recreation or for transportation). This interpretation is somewhat at odds with reports from our observers as well as those of others, ${ }^{23}{ }^{27}{ }^{28}$ which indicate that inexperienced skaters are more likely to wear protective equipment. As skill level and confidence increase, skaters appear to become less likely to don protective gear. Further investigation of the relationship between ability and type of skating is needed to help identify high risk groups for targeted interventions.

In-line skating is a relatively new sport that has quickly gained popularity. The results of the observational survey of skaters in the province of British Columbia indicate that the use of protective equipment by skaters is not widespread. The low rate of helmet wearing by in-line skaters is particularly striking in view of the fact that helmet use by bicyclists in British Columbia was nearly four times as great in $1995 .{ }^{26}{ }^{29}$ It is apparent that the relatively high rate of safety equipment use did not generalize from bicycling to in-line skating, even though many of the same individuals are probably engaging in these activities. Accordingly, policies and programs dedicated specifically to increase the use of protective equipment by skaters are needed to help reduce the frequency and severity of skating related injuries.

\section{Implications for prevention}

Just over one third of all in-line skaters were observed wearing any type of protective equipment. There remains tremendous opportunity to reduce the frequency and severity of injuries by increasing in-line skaters' use of protective equipment. The fact that the most commonly injured body area (that is, wrist, forearm) is the most often protected suggests that many skaters acknowledge the risk of injury to this area and take preventive action. More widespread recognition of the potential for injury may enhance the use of equipment to protect these areas. In particular, greater awareness of the risk of serious head injury may prompt greater use of helmets.

The use of protective equipment is required by both novice skaters and those with more advanced skills. Novice skaters are prone to fall as they acquire the necessary coordination and balance. Although more experienced skaters may be less likely to fall, when they do they are at risk of serious injury as a result of the higher speeds at which they tend to travel. Policies and programs that serve to increase the use of protective equipment by in-line skaters of all skill levels are needed to reduce the frequency and severity of skating related injuries.

This paper was supported in part by Grant Number R49/CCR415460-01 from the US Centers for Disease Control and Prevention. Its contents are solely the responsibility of the authors and do not necessarily represent the official views of the Centers for Disease Control.

1 International In-line Skating Association. In-line skating sales and participation statistics. www.iisa.org . 3-28-2000. Schuster M, Israeli A. Survey of injuries and protective gear worn by in-line skaters in public parks. Am $\mathcal{F}$ Phys Med Rehabil 1999;78:7-10.

3 Osberg JS, Schneps SE, Di Scala C, et al. Skateboarding: more dangerous than roller skating or in-line skating. Arch
morg Pediatr Adolesc Med 1998;152:985-91.

4 Warda L, Harlos S, Klassen TP, et al. An observational study of protective equipment use among in-line skaters. Inj Prev 1998;4:198-202.

5 American Academy of Pediatrics. Committee on Injury and Poison Prevention and Committee on Sports Medicine and Fitness. In-line skating injuries in children and adolescents. Pediatrics 1998;101:720-2.

6 Pudpud AA, Linares MY. In-line skating: a deadly pediatric activity? Pediatr Emerg Care 1997;13:376-9.

7 Jaffe MS, Dijkers MP, Zametis M. A population-based survey of in-line skaters' injuries and skating practices. Arch Phys Med Rehabil 1997;78:1352-7.

8 Mitts KG, Hennrikus WL. In-line skating fractures in children. F Pediatr Orthop 1996;16:640-3.

9 Powell EC, Tanz RR. In-line skate and rollerskate injuries in childhood. Pediatr Emerg Care 1996;12:259-62.

10 Malanga GA, Stuart MJ. In-line skating injuries. Mayo Clin Proc 1995;70:752-4.

11 Schieber RA, Branche-Dorsey CM. In-line skating injuries. Epidemiology and recommendations for prevention. Sports Med 1995;19:427-32.

12 Chong AL, Sunner PS, Deshpande SR. Wrist guards in in-line and conventional roller-skating injuries [letter]. Med f Aust 1995;162:444.

13 Ellis JA, Kierulf JC, Klassen TP. Injuries associated with in-line skating from the Canadian hospitals injury reporting and prevention program database. Can f Public Health 1995;86:133-6.

14 Schieber RA, Branche-Dorsey CM, Ryan GW. Comparison of in-line skating injuries with rollerskating and skateboarding injuries. $\mathcal{F} A M A 1994 ; 271: 1856-8$.

15 Calle SC. In-line skating injuries, 1987 through 1992 [letter]. Am f Public Health 1994;84:675.

16 Calle SC, Eaton RG. Wheels-in-line roller skating injuries. 7 Trauma 1993;35:946-51.

17 Heller DR, Routley V, Chambers S. Rollerblading injuries in young people. $\mathcal{F}$ Paediatr Child Health 1996;32:35-8.

18 Canadian Hospitals Injury Reporting and Prevention Program (CHIRPP). Injuries associated with in-line skating. CHIRPP Injury Reports 31 July 2000

19 Schieber RA, Branche-Dorsey CM, Ryan GW, et al. Risk factors for injuries from in-line skating and the effectiveness of safety gear. N Engl f Med 1996;335:1630-5.

20 Thompson DC, Rivara FP, Thompson RS. Effectiveness of bicycle safety helmets in preventing head injuries. A case-control study. FAMA 1996;276:1968-73.

21 Orenstein JB. Injuries and small-wheel skates. Ann Emerg Med 1996;27:204-9.

22 Young CC, Seth A, Mark DH. In-line skating: use of protective equipment, falling patterns, and injuries. Clin $\mathcal{F}$ Sport Med 1998;8:111-4.

23 Young CC, Mark DH. In-line skating. An observational study of protective equipment used by skaters. Arch Fam Med 1995;4:19-23. 
24 Jacques LB, Grzesiak E. Personal protective equipment use by in-line roller skaters. I Fam Pract 1994;38:486-8.

25 Adams SL, Wyte CD, Paradise MS, et al. A prospective study of in-line skating: observational series and survey of active in-line skaters-injuries, protective equipment, and training. Acad Emerg Med 1996;3:304-11

26 Foss, RD, Beirness DJ, Wilson RJ. Bicycle helmet use in British Columbia. 40th Annual Proceedings, Association for the Advancement of Automotive Medicine. Des Plaines, IL AAAM, 1996.
27 Seldes RM, Grisso JA, Pavell JR, et al. Predictors of injury among adult recreational in-line skaters: a multicity study. Am F Public Health 1999;89:238-41.

28 Williams-Avery RM, MacKinnon DP. Injuries and use of protective equipment among college in-line skaters. Accid Anal Prev 1996;28:779-84.

29 Foss, RD, Beirness DJ. Bicycle helmet use in British Columbia: effects of the helmet use law. Chapel Hill, NC: University of North Carolina Highway Safety Research Center, 2000.

\section{Olympic pin inhalation}

The 15 month old son of a New South Wales Supreme Court worker survived after swallowing an Irish Olympic 2000 official pin, complete with shamrock and five rings, reported the Belfast Telegraph newspaper in October. The pin, about the size of a 10 cent coin, was one of many given to the father who had been attached to the athletes' village. The family have kept the $x$ ray, which shows the pin in all its detail, for framing.

\section{Close shave with death}

Northern Ireland drivers are eating, applying make-up, and even shaving while driving, according to a survey undertaken by insurance company AXA Insurance. The survey also reveals that they read magazines, and get dressed-and undressed! (Belfast Telegraph, October 2000).

... while a sip of water cost driver $£ 90$

A woman who refused to pay a fixed penalty ticket when she was prosecuted for not being in control of her car because she was still holding her bottle of water as she drove off after taking a drink was eventually fined $£ 40$ with $£ 50$ costs by a court in Britain. She claimed a moral victory, based on the size of the supportive post bag that she received (Daily Telegraph (London), October 2000). 